\title{
16
}

\section{Junior Faculty Participation in Curricular Change}

\section{Judi Hetrick}

Miami University, Oxford, Ohio

Participation in curriculum change can be both a necessity and a professional landmine for junior faculty members. They do not, however, have to choose between sitting on the sidelines or sacrificing young careers by working for large-scale change. This chapter presents the elements of successful curriculum change, roles junior faculty can play, and roles thry should avoid -or accept with caution.

\section{INTRODUCTION}

uring my second year as a tenure-track faculty member, I was asked to serve on an interdepartmental group exploring how to change the journalism curriculum for my university. While the challenge was exciting, I had seen professors denied tenure when their focus wavered from the twin goals of classroom excellence and publication. Is it possible for junior faculty to participate successfully in curricular change? This chapter summarizes information in the literature on the process of curricular change, then defines roles that junior faculty can successfully adopt-or avoid.

Of course, many professors at all stages of their careers relish making changes to keep classes up to date, especially when their own research uncovers new information and insights they can pass along to students. As Ratcliff (1996) points out, about $5 \%$ of the university curriculum nationwide is officially changed every year as individual professors introduce new courses or one-time offerings. The actual percentage of change, though not recorded, is much higher, as instructors work within the space provided by brief and general catalog course descriptions to introduce new topics and techniques into their classrooms. 
Deeper, more systematic curricular change-change that goes beyond the individual course-is also a collegiate tradition as a power uniquely vested in the faculty. But as Levine (1978) noted 25 years ago, a Carnegie Council survey found that

not all faculty are equally involved in educational policy. Forty-three percent of the faculty indicate that a small group of senior professors has disproportionate power in decision-making, and $77 \%$ feel that junior faculty have too little say in the running of their departments. (pp. 424-425)

More recently, in their overview report on general education curricular reform at 71 New England colleges and universities, Arnold and Civian (1997) noted,

We are especially mindful of the differences arising from the competition between junior and senior cohorts within faculties. On one hand, there are professors and experienced associate professors whose futures with their institutions are for the most part assured and who have grown accustomed to influence and prestige on campus. On the other hand, there are assistant professors yet to achieve full acceptance, who often must struggle for the right to participate in decisionmaking at their institutions.... Even at institutions that were otherwise successful in bringing about change, cohort competition sometimes alienated segments of the faculty from each other and the newly created curriculum. (pp. 21-22)

Is it any wonder that, as Ratcliff (1996) noted, "Folk wisdom says that reforming undergraduate education is a troublesome, tumultuous, and difficult assignment" (p. 5). One reason the process may seem difficult is that much knowledge about curricular change is transmitted as an informal or folk process, one whose assumptions and techniques are not systematically articulated. The way curricular change occurs in any given field and at any given institution may be largely learned informally. The information that senior faculty know by virtue of their longer tenure is unpublished and often unexamined.

Junior faculty also have a myriad of other issues and stresses in their work lives. Research has shown that junior faculty work at least 48 hours a weck and are more likely to experience severe time constraints than their senior colleagues. They also sense a lack of collegiality and feel isolated (Finkelstein \& 
LaCelle-Peterson, 1992). These factors can prevent all but the most exceptional quick-starters from plugging into the informal faculty network early in their university careers.

Can junior faculty members learn to become a successful, vital part of a curricular reform effort, without jeopardizing their young careers? Their promotion and tenure depends heavily on both the work they do during their first few years in any faculty position, and on how that work is received by their senior colleagues. Participation in curricular reform efforts can drain time and energy away from research, writing, and classroom teaching -even without its capacity to alienate the very people who will decide the future of the junior faculty members.

Some go so far as to counsel junior faculty to be seen and not heard. In a first-person advice column for The Chronicle of Higher Education's Career Network, an assistant professor writing under a pseudonym gave a two-part answer to the question:

What is the best strategy for tenure?... Complete the specified requirements... and remain silent.... By remaining "silent," I don't mean not speaking; I mean not saying anything of substance that draws attention to one's thinking, and thereby lessening the possibility of petty conflicts entering into the tenure process. (Adso, 2002)

Such advice is obviously unrealistic and extreme, but the sentiment behind it is not unfamiliar to many junior faculty. Yet, despite some danger that may reside in speaking one's mind, work in broader curricular reform can also build bridges to senior colleagues and allow junior faculty to enter into a conversation with them that is vitally important for the faculty itself as a whole as well as for our students. Junior faculty share responsibility for the curriculum not just as it is taught in their own classrooms but also as it is offered by programs, departments, schools, and entire universities. Engaging in this process is a unique opportunity to serve both the academic institution and the larger society and to contribute to the broader conversation about the fundamental issues of higher education. Some junior faculty have no choice but to take part in the curricular change process, so learning more about it can help them manage the work and dodge some potential dangers.

\section{Defining Curricular Change}

Different authors use the terms "curriculum," "curricular reform," and "curriculum change" to describe a gamut of meta-instructional activities that 
range from fashioning an individual course syllabus to overhauling an entire university's core course of instruction. In this chapter, curricular change refers to the cooperative effort by a group of faculty, often with input from administrators and students, to bring institurionalized change to a key class, set of classes, or course of study at the program, departmental, divisional, college, or university level. A key attribute of successful curricular change, as opposed to instructional change, is that it does not rely on the teaching efforts of one individual. Rather, it is embedded in course descriptions, sequences of study, degree requirements, or other institutional requirements.

This type of change is foundational and can be transformational. As Keller (1982) noted in her study of Harvard University's influential revamping of its core curriculum,

Curriculum change is the most visible way in which that the institution [American higher education] adapts to changing conditions in our society. College faculties invest so much of their time and energy in debate over curricular structure because it provides a useful framework for discussing issues of a more complex, fundamental, and elusive sort. (pp. viii-ix)

\section{Conceptualizing Curricular Change}

Regardless of whether a change embraces a university-wide core set of classes or only one or a few offerings within a small program, participants can conceptualize these efforts in several different ways. And while any conceptualizations may be shaped by disciplinary worldviews, diverse approaches to theorizing, or even idiosyncratic local history, exploring them can be an important first step toward effectively taking part in the process.

Lindquist (1996), in an excellent introduction to the theories underlying the curricular change process, summarized four major approaches:

- Rational Planning. This is the research and development center model that believes successful change is based on reason and evidence.

- Social Interaction. This is the agricultural extension agent model that believes personal networks and communication are the keys to change. It looks at how groups of people-ranging from innovators and early adopters to laggards - react to new ideas and to each other.

- Human Problem-Solving. This is a modified group therapy model that looks at psychological resistance to change and offers techniques ranging 
from leadership training to focus groups to help people work through their problems and accept transitions.

- Political. As with any model that looks at vying factions, the political model sees people building coalitions with powerful individuals and with groups, and then leveraging authoritative decisions mandating change. (pp. 635-642)

Likewise, in discussing the desirability of team or collaborative leadership in an entire college or university, Bensimon and Neumann (1993) sketch conceptions of organizations that roughly parallel Lindquist's models: bureaucracies, where the rational prevails; collegiums, where human communication and consensus is at the fore; political systems; and symbolic systems, where change occurs through the manipulation of symbols.

Curricular change also can be conceptualized as a dichotomous process. Keller (1982) saw Harvard's as process entailing "the interplay between academic thought and politics" (pp. viii-ix). Cuban (1999) worried that at Stanford, broad subject matter change was sometimes used to avoid innovation in instructional techniques. He pointed out that the two often cannot be separated: "Professors seeking student understanding see the close intersection between subject matter and pedagogy. The two are entangled and need to be worked on simultaneously" (p. 170).

Not only are subject matter and ways of teaching entangled, but so are the approaches Lindquist (1996) outlines. After sketching the four different conceptualizations, he concluded that no one model is adequate to describe what happens in curricular change; a combination of theories is needed to understand the entire process. For example, the mere presentation of objective information, which should be adequate for a rational planning model, does not take social interaction into account. Simply looking at change as an exercise involving factions pro and con, as a political analysis might do, does not take into account the more subtle interpersonal interactions that shape our working lives.

A theoretical model that borrows from multiple approaches allows the different individuals involved in curricular change to fashion various roles and activities according to their strengths. This chapter follows that eclectic paradigm and assumes that any change process should be team-based and that those teams will be influenced by their members' participation in diverse disciplines and disciplinary cultures. Work by Kekale (1999), who compared the departments of sociology, ecology, physics, and history at two different Finnish universities, indicated links between disciplinary cultures 
and department leadership styles. He discovered that sociology professors, for example, have "the strong expectation that all the (important) decisions should be made collectively and democratically" (p. 226), while experimental physicists showed little interest in the topic at all, taking much leadership for granted and suggesting that any type of "leadership is good as long as it works" (p. 232).

Couple such differences in disciplinary worldviews with varied individual strengths and idiosyncrasies, and the suggestion of any general understandings about the change process may seem a gross oversimplification. But such an analysis can offer helpful guidance even if it cannot account for every local variation. Kekale's work warns that, depending on how disciplinarily diverse the group is, it is important to articulate different expectations of how the process will work and be led. Early awareness about these process issues may lessen problems further into the discussion. Acknowledging that more than one type of group and human interaction will come into play may ease frustrations with the process. It is easy to imagine how a physical scientist invested in a rational planning model may not at first understand a sociologist's devotion to democratic interaction.

But just as different assumptions can endanger the communication process, an understanding of different roles can enhance the way a group works. And knowing that the interactions will not follow one neat academic model can help junior faculty tailor their roles to their strengths.

\section{Determinants of Successful Curricular Change}

Researchers in the area of curricular change vary in some details, but they broadly agree that successful curricular change depends on good leadership, adequate resources, and rewards for participants; excellent planning and realistic goals; good information, particularly in planning and implementation; and good communication.

\section{Roles for Junior Faculty That May Facilitate the Curricular Change Process}

On the issues of leadership, resources, and rewards, all faculty, and especially junior faculty, may have limited influence, depending on their college or university's administrative and bureaucratic structure.

While planning and goal-setting may also be outside the realm of total faculty control, even junior faculty can advocate forcefully for their importance and begin to develop roles in the critical areas involving information and communication. Planning, including how to initially structure a process, will 
influence the success of any curricular change effort. Arnold and Civian (1997) stress the importance of structure.

The point cannot be overemphasized. Mundane as the matter seems, there is a payoff in attending to such simple matters as the way in which committees are appointed, who is consulted (or not) in the design process, and the effect of proposals on the status quo, as well as in hammering out the details of implementation in advance. This may all seem obvious, but our inquiry [into change at 71 schools] found that the obvious is often ignored, forgotten, or given short shrift. (p. 20)

Olguin and Schmitz (1996) additionally advise that a change process follow accepted procedures. In looking at initiatives that successfully transform curricula to add diversity, they found that successful change leaders "presented their plans as they would have any other plan in the campus governance process" (p. 454).

Effective curricular change needs to be thought of as ongoing and not as a one-time problem. The cost of reaching too far, and then failing, can be high.

Virtually all of the campuses in our study that attempted major change failed to accomplish it in the face of enormous political and financial pressures. Embittered visionaries involved in the failed change frequently retreated from active campus participation, so great was their disappointment in the compromises reached... Where dramatic change is desirable, it is best accomplished in modest stages. (Civian, Arnold, Gamson, Kanter, \& London, 1996, p. 653)

Change on a smaller scale, such as the departmental level, is more likely to be successful than broad, sweeping change. Civian et al. suggest that faculty feel most comfortable within their departments and so are more comfortable dealing with change based there: "Faculty even in small colleges view their departments as home, and they are likely to accept change emanating from their departments... Faculty are most resistant to college or institution-wide curricular change (p. 648)." One reason for this comfort may be that their voices are louder, and their influence is therefore greater at home (Levine, 1978).

\section{Roles Junior Faculty Can Play}

Whether they are working within the department or the larger institution, many junior faculty are just as qualified as senior colleagues to work with information 
and communication. Tasks in these areas are likely to be numerous and varied enough that junior faculty members can tailor how much they do to match both their expertise and the amount of time they wish to invest in the process.

Planning stage data-gatherer. While change is being planned, the need for information is great, whether or not you subscribe to the rational planning model. The types of information that can be gathered and shared include both benchmarking data and information from professional organizations and outside disciplinary colleagues. This can help answer many critical questions. What are other institutions doing in the area you are trying to change? What are the current best teaching practices in your field, both nationally and internationally? How might the changes you are considering affect accreditation in your field? What do experts among the broader community of your colleagues say about contemporary curricula? What studies or pilot programs have been tried or are in process? What articles have been written that address the issues you also are addressing?

Constituent and special-interest advocate. Junior faculty can advocate for constituencies not represented on the curricular change team, seeking representation or other ways to have their voices heard throughout the process. These constituencies could range from students and faculty groups (including junior faculty) to outside interests, such as alumni, employers, or graduate schools. They could also include acadenic concerns. How does the new curriculum deal with diversity? With international issues? With problem-solving or team-building skills? One way to advocate for these constituencies is by polling them. What do your alumni, students, or outside interests think of the current curriculum? What suggestions do they have for change? If your disciplinary background includes training in scientific surveys, this type of research could be an ideal avenue for junior faculty participation. But even without this background, if scientific generalizability is not a goal, anyone can gather helpful information for relatively low cost through the use of online survey instruments such as Flashlight or surveymonkey.com. Focus groups can also be convened to give qualitative data about the current curriculum and ideas for change.

As members of content specialty/instructor teams. One of the earliest projects that aimed to transform curricula with feminist theory, at the University of Arizona in the 1980s, employed interdisciplinary weekly seminars for faculty. Many of the seminar leaders, especially early in the program, were junior feminist faculty (Aiken, Anderson, Dinnerstein, Lensink, \& MacCorquodale, 1988). While the seminars were in large part considered a part of a successful curricular transformation project, the issue of who best teaches whom is also a 
complicated one. The down side of junior faculty instructing senior faculty is touched on in the next section.

Pilots. Once a new curriculum is designed, it will need to be tested with small groups of students before being implemented across the board. Because junior faculty are frequently involved in developing courses as a part of their new jobs, the development and teaching of pilot courses that meet the goals of the new curriculum may be a natural area for their involvement in the larger process.

Assessment-stage data-gatherer. Once new courses are introduced and tried, they must be assessed. As Ferren and McCafferty (1992) have noted, "Without thoughtful attention to the implementation of new requirements, curricular reform will not bring the desired results" (p. 90). Again, junior faculty expertise may come into play here, or becoming part of the assessment team may help junior faculty learn techniques that they can apply to their own work as their careers develop.

Communicators. The good communication that is so important to the success of a curricular change effort can be formal or informal, person-to-person or mediated, part of an ongoing process or carefully orchestrated for special occasions. Within the array of communication tools and techniques, most junior faculty can find jobs that play to their strengths, be it designing a web page or moderating a listserv email discussion, talking to colleagues one-onone, or moderating a "town meeting" with a special constituency.

Persuaders and peacemakers. Because of the high stakes involved in the curricular change process, such efforts are likely to encounter strife and resistance to change. Middendorf (1998) advocates gathering information from those who will be affected by the change in order to understand any resistance. "To understand general concerns, you need only to know what makes all people resist change. These include time, motivation, experience, control, expertise, effort, fear, and rewards" (p. 206). Resistance can then be mitigated as concerns are addressed. But because political as well as personal forces will be at work, the process will also need peacemakers to broker comprises (Cuban, 1999).

\section{Roles for Junior Faculty to Approach Warily}

As any change is planned and strategized, the literature points to a few key roles that most junior faculty may not be established enough to take, that may endanger their other work, or that may inhibit their long-term effectiveness.

Primary team-builder. This leadership role is key to any group effort but is "highly demanding. Doing it well requires a high level of commitment and 
a steep investment of time" (Bensimon \& Neumann, 1993, p. 12). Unless junior faculty workloads are carefully structured to allow for the time and effort required, accepting an assignment as team leader may be overwhelming.

Sole or main content specialists/instructors. While junior faculty may have important new content specializations, successful teaching, even of other teachers, is a complicated dynamic linked to more than knowledge. Despite the successes of the University of Arizona's early feminist curricular transformation process, its leaders also chronicled resistance linked in part to faculty status. As described in Aiken et al. (1988), a group of "relatively young, less privileged feminist women (the majority of them untenured) [taught] relatively older, generally powerful men" (p. 139). This experience led to advice that furure reaching reams include more senior faculty and that the seminar participants be more diverse in status: "It is only realistic to recognize that the power of the individuals presenting the material has much to do with its acceptance. We would also suggest a balance of junior and senior, tenured and untenured participants" (p. 156).

Opinion leader. Not all leaders are officially designated, and anyone working for change should not underestimate the importance of having informal opinion leaders on their side. Middendorf (2000), who recommends identifying opinion leaders through interviews with faculty, has written,

They are the most important faculcy in facilitating a change regarding teaching because, even though they usually have no official position of power, they do have considerable influence on others' atritudes and behaviors. They serve as the hub of the faculty communication network. They make careful judgments and good decisions, and they decrease uncertainty because their peers trust their evaluation. (p. 85)

While junior faculty could be opinion leaders under some circumstances, this role is generally an informal one that evolves through time. Junior faculty should consider trying to learn who are the established opinion leaders and be wary of trying to force themselves into that role.

Mavericks. Because the goal of curricular change is to implement lasting change that gocs beyond one instructor's efforts, working outside the group process generally is not effective. Specifically, Keller (1982) reports on changes at Harvard in 1968-1969: "Two new courses, Social Change in America (Social Relations 148) and Radical Perspectives on Social Change (Social Relations 149) were organized by Students for a Democratic Society, headed (or fronted) by two junior faculty members" (p. 30). While the courses were taught to up to 1,000 students, the institution never adopted them. In looking at less radical 
change, Middendorf (1998) has discovered that those faculty who gain reputations as cutting-edge classroom innovators rarely are effective at single-handedly bringing about lasting change. These innovators are "useful as testers or demonstrators of change, but usually not as opinion leaders" (p. 210).

\section{Conclusion}

When the process begins to change a curriculum, every faculty member, including those just hired or only a few years into their jobs, has the choice of becoming a change agent, a resister, or someone who tries to sit on the sidelines while others participate. I share the assumption found in most of the literature that working for change is usually a positive activity that can and should improve what and how we teach and what and how our students learn. Advice published for people working in $\mathrm{K}-12$ education applies to college and university curriculum work as well.

A change facilitator can be anyone... It's not important where on the organizational chart the person falls; what is important is that facilitators support, help, assist, and nurture. Sometimes their task is to encourage, persuade, or push people to change, to adopt an innovation and use it in their daily schooling work. (Hord, Rutherford, HulingAustin, \& Hall, 1987, p. 3)

Not every change should be made, and not every change should be made at every institution. Levine (1978) noted that "successful curriculum change is most likely when an innovation is consistent with the norms, values, and traditions of the environment in which it is being introduced" (p. 432). Without such consistency, not only may reform fail, but it can exact a heavy personal toll. Civian et al. (1996) state, "Faculty members or administrators who choose to crusade for programs that dramatically alter the status quo are not only unlikely to succeed, but may end up bitter and disillusioned" (p. 654). Junior faculty who have staked too much may also end up being denied tenure or feel the need to leave.

However, if junior faculty choose to participare in the change process, or if their participation is not optional, an understanding of how it has worked and how it can be conceptualized, planned, and customized can be a key to effective and efficient participation in the process. That participation is not without risks, but it also promises rewards.

Civian et al. (1996) have shown one clear benefit of working for curricular change. "By and large, faculty members who have been involved in curricular 
change report that they find the process of designing and implementing new curricula to be intellectually stimulating and professionally satisfying" (p. 653). Participation with a curricular change committee can lessen feelings of isolation and lack of collegiality commonly reported by new faculty. It also can acquaint those who will step into senior roles in a few short years with traditions, history, and folk wisdom of their institutions, while at the same time they begin to make their marks on them.

What at first glance may seem to be a simple practical decision about where a junior faculty member can best invest limited energy, a decision to participate in curricular change can also lead to personal and spiritual growth. In The Courage to Teach, Palmer (1997) advocates for a holism that calls people to teach as fully integrated individuals and members of communities. Instead of playing games-remaining silent for fear of retribution-by joining with others for appropriate change we can begin to see how our work as individuals and in individual classrooms fits into a larger curriculum and how we as individuals fit into and help maintain the larger academic community.

\section{REFERENCES}

Adso, J. (2002, February 27). Figuring out what counts in the tenure game. Chronicle of Higher Education Career Network. Retrieved November 9, 2002, from http://chronicle.com/jobs/2002/02/2002022701c.htm

Aiken, S., Anderson, K., Dinnerstein, M., Lensink, J. N., \& MacCorquodale, P. (1988). Changing our minds: The problematics of curriculum integration. In S. H. Aiken (Ed.), Changing our minds: feminist transformations of knowledge (pp. 134-163). Albany, NY: State University of New York Press.

Arnold, G., \& Civian, J. T. (1997, July/August). The ecology of general education reform. Change, 2X(4), 19-23.

Bensimon, E. M., \& Neumann, A. (1993). Redesigning collegiate leadership: Teams and teamwork in higher education. Baltimore, MD: Johns Hopkins University Press.

Civian, J. T., Arnold, G., Gamson, Z. F., Kanter, S., \& London, H. B. (1996). Implementing change. In J. G. Gaff, J. L. Ratcliff, \& Associates (Eds.), Handbook of the undergraduate curriculum: $A$ comprehensive guide to purposes, structures, practices, and change (pp. 647-660). San Francisco, CA: Jossey-Bass.

Cuban, L. (1999). How scholars trumped teachers: Change without reform in university curriculum, teaching, and research, 1890-1990. New York, NY: Teachers College Press. 
Ferren, A. S., \& McCafferty, J. K. (1992). Reforming college mathematics. College teaching, 4O(3), 87-90.

Finkelstein, M. J., \& LaCelle-Peterson, M. W. (1992). New and junior faculty: A review of the literature. In M. D. Sorcinelli \& A. E. Austin (Eds.), Developing new and junior faculty (pp. 5-14). San Francisco, CA: Jossey-Bass.

Hord, S. M., Rucherford, W. L., Huling-Austin, L., \& Hall, G. E. (1987). Taking charge of change. Alexandria, VA: Association for Supervision and Curriculum Development.

Kekale, J. (1999). "Preferred" patterns of academic leadership in different disciplinary (sub)cultures. Higher Education, 37, 217-238.

Keller, P. (1982). Getting at the core: Curricular reform at Harvard. Cambridge, MA: Harvard University Press.

Levine, A. (1978). Handbook on undergraduate curriculum: A report for the Carnegie Council on Policy Studies in Higher Education. San Francisco, CA: Jossey-Bass.

Lindquist, J. (1996). Strategies for change. In J. G. Gaff, J. L. Ratcliff, \& Associates (Eds.), Handbook of the undergraduate curriculum: $A$ comprehensive guide to purposes, structures, practices, and change (pp. 633-660). San Francisco, CA: JosseyBass.

Middendorf, J. K. (1998). A case study in getting faculty to change. In M. Kaplan \& D. Lieberman (Eds.). To improve the academy: VoL. 17. Resources for faculty, instructional, and organizational development (pp. 203-224). Stillwater: OK: New Forums Press.

Middendorf, J. K. (2000). Finding key faculty to influence change. In M. Kaplan \& D. Lieberman (Eds.), To improve the academy: Vol. 18. Resources for faculty, instructional, and organizational development (pp. 83-93). Bolton, MA: Anker.

Olguin, E., \& Schmitz, B. (1996). Transforming the curriculum through diversity. In J. G. Gaff, J. L. Ratcliff, \& Associates (Eds.), Handbook of the undergraduate curriculum: $A$ comprehensive guide to purposes, structures, practices, and change (pp. 436-456). San Francisco, CA: Jossey-Bass.

Palmer, P. J. (1997). The courage to teach: Exploring the inner landscape of a teacher's life. San Francisco, CA: Jossey-Bass.

Ratcliff, J. L. (1996). What is a curriculum and what should it be? In J. G. Gaff, J. L. Ratcliff, \& Associares (Eds.), Handbook of the undergraduate curriculum: $A$ comprehensive guide to purposes, structures, practices, and change (pp. 5-29). San Francisco, CA: Jossey-Bass. 